tion of two or more proteins in a complex. One of Lieber's intended objects of study is the transcriptional regulation complex dubbed the 'enhanceosome', which consists of eight proteins.

The most promising line of research in terms of large-scale application is that of semiconductor nanowires. Having a similar diameter to carbon nanotubes, semiconductor nanowires differ importantly in having electrical properties that can be readily modulated and controlled. 'What happens at the surface really affects the whole material,' said Lieber. In effect, the binding of a single molecule to a nanowire can be detected by a change in conductance. And with these few words, an enormous valley of opportunity opens in which silicon chip microarray technology is seen to give way to much smaller grids of semiconductor nanotubes. As Lieber explained, using such a grid-the junctions of which operate as read-in and read-out nodes-one could 'exploit all the chemistry of chip technology without the need for fluorophore labelling'. This is because the wires are so sensitive that amplification of the original signal by light emitting chemical reactions (as is the case with conventional microarrays) would be unnecessary. Lieber sees a future where direct electrical measurements of binding essentially replace labels and optical scanning. In a proof-ofprinciple experiment, he has already shown that such functional nanogrids are feasible (Duan et al., 2001). Companies are already showing interest in developing such technology into commercial screening kits, according to Lieber.

As in all branches of nano research, the potential seems immense, but massive interdisciplinary research is still needed to make the ideas applicable and broaden their scope. Information emerging from the human genome project will turn up countless targets for nano research. 'Some things will emerge that are commercially useful,' noted Lieber; biosensors, for instance, could make an impact fairly soon. Despite the exaggerated claims of the past, venture capitalists in the USA are clearly showing interest in nanotechnology. 'My hope is that there are some very tangible effects that the lay person will see,' Lieber concluded. These may still be a few years off, but this time the claims are not pure 'nanohype'.

\section{REFERENCES}

Duan, X., Huang, Y., Cui, Y., Wang, J. and Lieber, C.M. (2001) Indium phosphide nanowires as building blocks for nanoscale electronic and optoelectronic devices. Nature, 409, 66-69.

Oesterhelt, F., Oesterhelt, D., Pfeiffer, M., Engel, A., Gaub, H.E. and Müller, D.J. (2000) Unfolding pathways of individual bacteriorhodopsins. Science, 288, 143-146.

Woolley, A.T., Guillemette, C., Cheung, C.L., Housman, D.E. and Lieber, C.M. (2000) Direct haplotyping of kilobase-size DNA using carbon nanotube probes. Nature Biotech., 18, 760-763.

\section{Andrew Moore}

DOI: 10.1093/embo-reports/kve035

\title{
What is patent-worthy?
}

\section{Due to differing legal standards for patentability, applications for gene patents face different outcomes in various countries}

The United States Patent and Trademark Office granted four gene patents to Sagami Chemical Research Institute in Sagamihara City for human cDNAs related to liver function and cell division, although the exact function and mechanism of the coded proteins were unknown. Earlier last year, the Japanese Patent Office had rejected these applications, demonstrating, according to the Japanese business newspaper Nikkei (January 8, 2000), that the USPTO has a more relaxed stance in granting gene patents.

Indeed, it is not unusual that a patent for the same invention is granted in one country and denied in another, because the legal tests for patentability are not the same in every jurisdiction. Although inventors can file under the Patent Cooperation Treaty with most patent offices in the world to receive protection of their invention, the individual outcome still depends on the patent office in each country. Particularly when it comes to granting patents for expressed sequence tags (ESTs) - when found by sequencing or by mere homology searches in databases - the USPTO has been shown recently to decide differently from its European and Japanese counterparts.

However, a comparative statement, such as the one the Japanese newspaper made, may be too simplistic. 'Among patent practitioners, the laws of the US, Europe and Japan are considered to be the most developed in the biotech field,' S.Peter Ludwig, senior member of Darrby \& Darby PC, an intellectual property law firm in New York, said, 'but they are certainly not "equivalent". In some respects
Japanese law on patentability is more lenient than US law, in others, more stringent.'

International differences in intellectual property laws and their consequences for the biotech industry were among the topics of the Biolapan 2000 symposium in September last year in Tokyo. Patent attorneys and patent officers from Japan, Australia, the UK, Germany and the United States expounded about international strategies for biotech patents. Among the speakers, Janis K. Fraser of Fish \& Richardson PC, an intellectual property law firm in Boston, MA, compared the criteria for patentability of genes that the US, European and Japanese patent offices apply. All three accept patent applications for chromosomal genes, cloned cDNA and virtual cDNA discovered by data mining. According to 
Fraser, all three patent offices ask the same questions: 'first: is the full sequence of the gene disclosed? In Europe and Japan, if only a partial sequence is disclosed, is there a straightforward way to obtain the full sequence? Secondly: is the gene novel and non-obvious? And thirdly: is a specific and plausible use for the gene or its encoded protein disclosed?' well as in the private sector. In a joint statement in March last year, President Clinton and Prime Minister Tony Blair urged private companies to 'make raw [DNA] data publicly available' and to make 'responsible use of patents.' Their statement seemed to be directed at the activities of certain private data marketing companies—such as Celera Genomics

It is not unusual that a patent for the same invention is granted in one country and denied in another, because the legal tests for patentability are not the same in every jurisdiction

Inconsistencies arise when patent offices make differing decisions based on the completeness of the genetic information disclosed in the application. For instance the policy of the USPTO does not now allow claims broad enough to cover a whole cDNA sequence if only a partial cDNA sequence has been disclosed, Fraser continued. In contrast she said, 'the EPO (European Patent Office) and JPO (Japanese Patent Office) consider a partial sequence adequate if it were clear that the full sequence could be obtained without undue burden.' However, the EPO and JPO are not so lenient as the USPTO on the requirement for novelty and non-obviousness, Fraser said, because of fewer case laws in these countries. In the shrinking middle ground, the EPO considers a gene non-obvious 'when neither the purified protein nor any homologous gene is catalogued in the prior art.'

As for the utility requirement, Fraser pointed out that USPTO demands a 'specific and plausible' description of the intended use of an invention to accept a patent application. For example, the intended use of proteins as shampoo ingredients or of transgenic mice as snake food would not be sufficient. 'A mere statement that a gene or protein could be used in therapy, though based on sound logic, is rarely enough to satisfy the USPTO,' she said. On this point, the utility rules of the EU and Japan are similar to the US, she added.

The differing standards for the patentability of a discovery, particularly regarding USPTO's policy, have already raised concerns and criticism. Researchers, economists and politicians fear that unfettered patenting of DNA sequences will eventually hinder research in academia as

and Incyte- that have been engaged in high-volume sequencing of human DNA and collection of genes and genetic variations.

Earlier, in April 1999, the Japan Bioindustry Association offered opinions regarding the patentability of DNA fragments and strongly criticised a 1998 US patent for human kinase homologs granted to Incyte Inc. in Palo Alto, CA. 'We are worried that if patenting of this type of invention becomes common practice it will seriously affect the entire global bioindustry,' stated the industry trade group. 'We in JBA consider that applications in relation to this type of EST invention should not be patented.' However, JBA acknowledges the utility of an EST invention as a diagnostic probe 'for a specific disease where the association with the disorder is clearly established.'

There has been a steady drumbeat of criticism from other countries, as well as from companies from the US, expressing concern that the

USPTO's thresholds for finding utility and non-obviousness are too low, and that the patents it issues are too broad

The JBA opinion represents the approximately 250 member companies, which asked the JPO to consider their standpoint when discussing the matter with the US and EU, a spokesperson said. As a nonprofit organisation, JBA is chartered by the Japanese Ministry of International Trade and Industry, but is independent of it. JPO is officially a part of MITI, but in terms of policy-especially day-to-day rulings on patent applications-it has substantial autonomy.

In contrast to the USPTO and the JPO, the EPO is not under the jurisdiction of any European government or the European
Union. Rules are set up by the European Patent Organisation, which represents the 20 contracting states-the EU member states as well as Switzerland, Monaco, Turkey, Cyprus and Liechtenstein. Although independent of the EU, the EPO has largely adopted its guidelines for patenting in the biotechnology sector, which puts restrictions on the patenting of ESTs similar to the guidelines that the JPO follows.

'To my knowledge, the USPTO is the only major patent office that has issued patents where the principal claims focus on the ESTs themselves,' Robert Kneller, Professor at the Intellectual Property Research Center for Advanced Science and Technology at the University of Tokyo said. 'The official position of the USPTO is that EST claims should not be treated differently from other claims. Representatives of the EPO have made statements suggesting that the EPO does not believe that claims focused on ESTs are acceptable.' JPO has also stated that the likelihood of accepting EST claims is low. Nevertheless, I suspect that JPO agrees with [the JBA opinion] that if ESTs have a clear diagnostic utility and are part of an inventive process, patents claiming those ESTs for such a use could be issued,' Kneller said.

However, it is unlikely that the JBA's criticism will affect the USPTO's policy on granting patents for genes. 'I do not think the JBA opinion by itself will affect the USPTO,' Kneller said, 'and it certainly

will not stop applicants from filing ESTbased claims with the USPTO if they think there is a reasonable chance that the USPTO will grant patents.' On the other hand, there has been a steady drumbeat of criticism from other countries as well as from companies from the US, expressing concern that the USPTO's thresholds for finding utility and non-obviousness are too low, and that the patents it issues-in particular the Incyte kinase patent-are too broad. 'The USPTO is sensitive to these criticisms and has tightened up its utility and enablement requirements,' Kneller described recent changes in the 


\section{analysis}

USPTO's policy. 'It is also seeking input from the scientific community as to what is obvious and predictable in the field of genome science.'

Indeed, changes are already underway. Ludwig cites a recent decision by the Court of Appeals for the Federal Circuit in Washington, DC (the court of appeal for all patent cases in the US) that elaborated the standard for compliance with the written description requirement of US Patent Law. To comply, a patent specification must include sufficient information to establish that the inventor is in possession of the claimed invention. 'To my knowledge there is no counterpart to this requirement in the patent law of most developed countries,' Ludwig said, 'in this sense, US patent law is more stringent than the laws in these other countries.'

One of the newest changes to patent law is that the USPTO has shortened the publication time for patent applications to 18 months. Shannon Mrksich of Brinks Hofer Gilson \& Lione, a patent law firm in Chicago, expects that the November rule change will not be likely to accelerate academic research, but that industry will 'be reading the patents like nuts to see what competitors are up to, because lead time in development is everything.' On the other hand, she thinks that no company would refrain from filing a patent application with the USPTO to avoid this potential competitive risk.

\section{Sandra Katzman}

The author is a freelance journalist in Yokohama, Japan.

E-mail: skatzman@nasw.org

DOI: 10.1093/embo-reports/kve036 